\title{
Alfa -1 reseptör blokeri ilaçların benign prostat hiperplazisi tedavisindeki kullanımlarının önemli noktaları ve yeni klinik kullanım alanları
}

\author{
Important points of usage of alpha-1 receptor blocker drugs in the \\ treatment of BPH and new areas of clinical usage
}

Ali Atan®

\section{öz}

Alfa-1 reseptör blokeri ilaçlar elli yıla yakın bir süredir BPH ile ilişkili AÜSY tedavisinde üroloji pratiği içerisindedir. Yaygın olarak kullanılan alfa-1 reseptör blokeri ilaçlar alfuzosin, doksazosin, terazosin, tamsulosin ve silodosindir. Bu ilaçlar BPH ile ilişkili AÜSY tedavisinde ilk basamak tedavi olarak kabul edilmektedir. Tüm alfa-1 reseptör blokerler benzer etkinliktedir ve aralarında etkinlik açısından belirgin bir fark bulunmamıştır. Alfa-1 reseptör blokeri ilaçlar ile idrar akım hızında \%20-40 düzeyinde bir artış ve semptomlarda \%30-50 düzeyinde bir azalma sağlanmıştır. Son yıllarda alfa-1 reseptör blokeri ilaçların yeni klinik kullanım alanları geliştirilmiştir. Bu yeni klinik kullanım alanları akut üriner retansiyon ve üriner sistem taş hastalığıdır. Tüm klinik kullanım alanlarında, alfa-1 reseptör bloker seçimi kardiyovasküler sistem ve cinsel fonksiyonlar üzerindeki yan etkileri dikkate alınarak yapılmalıdır.

Anahtar Kelimeler: BPH, alfa bloker, medikal ekspulsif tedavi, üriner retansiyon

\section{Gíriș}

Benign Prostat Hiperplazisi (BPH) ile ilişkili alt üriner sistem yakınmalarının (AÜSY) oluşumunda prostatın dinamik ve statik komponentleri ile beraber mesanenin etkili olduğunu biliyoruz. BPH ile ilişkili AÜSY oluşumunda prostatın dinamik komponenti denildiğinde prostat stromasında bulunan düz kas tonusunun çıkım üzerindeki etkisi kastedilmektedir. BPH ile ilişkili AÜSY oluşumunda prostatın statik komponenti ise büyümüş prostatın prostatik uretraya olan kitlesel etkisini ifade etmektedir. $\mathrm{BPH}$

Gazi Üniversitesi Tıp Fakültesi, Üroloji Anabilim Dalı, Ankara, Türkiye

Yazışma Adresi/ Correspondence:

Prof. Dr. Ali Atan

Birlik mahallesi, 396 sokak, 14/11, Çankaya Ankara, Türkiye

Tel. $\quad$ +905324242082

E-mail: aliatanpitt@hotmail.com

Geliş/ Received: $\quad 15.05 .2020$

Kabul/ Accepted: $\quad 02.06 .2020$

\section{ABSTRACT}

In the urology practice, alpha-1 receptor blocker drugs have been for the treatment of LUTS associated with BPH for about fifty years. The commonly used alpha-1 receptor blocker drugs are alfuzosin, doxazosin, terazosin, tamsulosin and silodosin. These drugs are considered as first-line therapy for the treatment of LUTS associated with BPH. All alpha- 1 receptor blockers have similar efficacy and there was no significant difference in terms of the efficacy among them. With alpha-1 receptor blocker drugs, a $20-40 \%$ increase in urine flow rate and a 30 $50 \%$ decrease in symptoms were achieved. In recent years, new areas of clinical usage of alpha-1 receptor blocker drugs have been developed. These new areas of the clinical usage are acute urinary retention and urinary tract stone disease. In all areas of clinical usage, the choice of alpha-1 receptor blockers should be made considering the side effects on the cardiovascular system and sexual functions.

Keywords: BPH, alpha blocker, medical expulsive treatment, urinary retention

ile ilişkili AÜSY oluşumunda mesanenin özellikle depolama ile ilişkili yakınmaların oluşumundan sorumlu olduğu kabul edilmektedir. Günümüzde BPH ile ilişkili AÜSY tedavisi de bu hedeflere göre planlanmaktadır. Alfa-1 reseptör blokeri ilaçların üroloji pratiğinde ilk ve en sık olan kullanım alanı BPH ile ilişkili AÜSY tedavisidir. Prostat stromasının ve mesane boynunun, alfa reseptörlerden zengin olduğunun saptanmasından sonra alfa-1 reseptör blokeri ilaçların BPH ile ilişkili AÜSY tedavinde kullanımı gündeme gelmiştir. ${ }^{[1]}$ Normal bir prostat içerisinde stroma/epitel oranı $2 / 1$ iken BPH'nin erken döneminde bu oran 4/1'e değişmektedir. ${ }^{[2]} \mathrm{BPH}$ hastalarında stromanın gevşetilmesi ile prostatik uretradaki direncin azaltılacağı ve yakınmaların düzeleceği düşüncesiyle ilk kullanılan alfa reseptör blokeri ilaç, alfa-1 ve alfa-2 reseptörleri etkileyen Fenoksibenzamindir. Fenoksibenzaminin her iki alfa reseptör grubunu etkilemesine bağlı ortaya çıkan yan etkilerden dolayı bu ajanın BPH tedavisinde uzun süreli klinik kullanımı mümkün olmamıştır. Daha sonra selektif olarak 
adlandırılan yani sadece alfa-1 reseptörleri etkileyen ilaçlar geliştirilmiştir. İlk olarak kısa etkili Prazosin, BPH ile ilişkili AÜSY tedavisinde kullanılmıştır. Ancak sık dozaj nedeni ile bu ajanda uzun süreli kullanım alanı bulamamıştır. Daha sonra hem selektif hem de uzun etkili olan ajanlar geliştirilmiştir. Günümüzde sıklıkla kullandığımız Terazosin (5 $\mathrm{mg} /$ ün), Doksazosin (4 ve $8 \mathrm{mg} /$ gün), Alfuzosin (10 mg/ gün), Tamsulosin $(0,4 \mathrm{mg} / g u ̈ n)$ ve Silodosin ( $8 \mathrm{mg} / g u ̈ n)$ bu gruba ait ilaçlardır. Daha ileri çalışmalar ile alfa-1 reseptör blokeri ilaçlarda kendi içerisinde üroselektif ve üroselektif olmayanlar olarak iki gruba ayrılmıştır. Farmakolojik çalışmalarda alfa-1 reseptörlerin, alfa- $1 \mathrm{a}$, alfa- $1 \mathrm{~b}$ ve alfa- $1 \mathrm{~d}$ gibi bazı alt tiplerinin olduğu da saptanmıştır. Alfa-1a reseptörlerin özellikle prostat içerisinde, alfa- $1 \mathrm{~b}$ reseptörlerin vasküler sistem, santral sinir sistemi, dalak ve akciğerde ve alfa-1 d reseptörlerin mesane ve spinal kordda bulunduğu gösterilmiştir. Çoğunlukla alfa-1a reseptörünü bloke eden tamsulosin ve silodosin farmakolojik üroselektif olarak kabul edilmektedir. ${ }^{[3]}$

Yapılan kapsamlı çalışmalar sonucunda alfa-1 reseptör bloker tedavisi, BPH ile ilişkili AÜSY tedavisinde ilk basamak tedavi olarak kabul edilmektedir. Bu ilaçların etkinliği birkaç günde başlamakta, 1-2 haftada maksimuma ulaşmaktadır. Bu nedenle hastaların ilk kontrollerinin 4-6 hafta sonra, ardışık kontrollerin ise 6-12 aylık aralarla yapılmasının uygun olduğu belirtilmektedir. ${ }^{[4]}$ Tüm alfa-1 reseptör blokerlerinin benzer etkinlikte olduğu ve aralarında etkinlik açısından belirgin bir farkın bulunmadığı belirtilmektedir. Meta-analiz çalışmalarının sonuçlarına göre alfa-1 reseptör blokeri ilaçlar ile idrar akım hızında \%20-40 (2-3 $\mathrm{mL} / \mathrm{sn}$ ) düzeyinde bir artış olduğu saptanmıştır. Bu artış plasebo kullanımı ile olan düzelmenin 10-15 kat daha fazlasıdır. Semptomatik düzelme açısından değerlendirme yapıldığında ise alfa-1 reseptör blokeri ilaçlar ile \%30-50 (4-6 puan) düzelme olur iken plasebo ile bu düzelme sadece $\% 10-20$ dir. $^{[5-7]}$

Alfa-1 reseptör blokeri ilaçların etkisinin BPH ile ilişkili AÜSY'nın şiddeti arttıkça daha fazla olduğu gösterilmiştir. ${ }^{[8]}$ Ancak etkinliğin mesane çıkım tıkanıklığı ile korele olmadığ bulunmuştur. ${ }^{[4]} \mathrm{Bu}$ ilaçlar küratif değildir, semptomatik düzelme sağlamaktadır. Bu nedenle kullanıldığı süre içerisinde faydalı olmaları beklenir. Ancak uzun süreli kullanım ile etkinlik kaybı endişe konusudur. Klinik çalışmalarda bu ilaçların en uzun kullanıldığı süre 4 yıldır. Bu süreye kadar hem IPSS hem de idrar akım hızı üzerinde bu ilaçların faydalı olduğu gösterilmiştir. ${ }^{[6]}$

Alfa-1 reseptör blokeri ilaçlar ile ilgili bazı tartışmalı konular vardır. Bu konulardan bir tanesi, bir alfa-1 reseptör blokeri başarısız olduğunda başka bir alfa-1 reseptör blokerinin fayda sağlayıp sağlamadığıdır. Ülkemizde yapılmış ve uluslararası dergilerde yayımlanmış çalışmalarda bu konuda farklı sonuçlar vardır. Şamlı ve Dinçel'in çalışmasında BPH ile ilişkili AÜSY olan 25 hastaya Doksazosin, 25 hastaya Terazosin 3 ay süreyle verilmiştir. Bu tedavi süresi sonrasında semptom düzeyinde ve maksimum idrar akım hızında \%20'den az düzelmenin olduğu hastalarda ilaç değişimi yapılmıştır. ${ }^{[9]}$ Bir diğer çalışmada ise $\mathrm{BPH}$ ile ilişkili AÜSY olan hastalara 3 ay süre ile Terazosin verilmiş, sonra 1 ay ilaçsız bırakılarak sonraki 3 ayda Alfuzosin kullanılmıştır. İlk 3 ay ile ikinci 3 ay sonuçları karşılaştırılmıştır. $^{[10]} \mathrm{Bu} 2$ çalışmada ilaç değiş̧iminin ek fayda sağlamadı$\breve{g} ı$ bulunmuştur. Ancak Karadağ ve ark.'nın daha yeni bir çalışmasında ise ilk 8 hafta bir grup hastaya Tamsulosin, diğer grup hastaya ise Alfuzosin verilmiştir. Arada boşluk olmadan ikinci 8 haftada iki grup arasında ilaç değişimi yapılmıştır. Yani ilk olarak tamsulosin alanlar alfuzosin, ilk olarak alfuzosin alanlar tamsulosin kullanmışlardır. Araştırıcılar ilaç değişiminin \%25 ek fayda sağladığını belirtmektedirler. ${ }^{[11]}$ Bir diğer tartışmalı konu hasta yaşının alfa-1 reseptör bloker tedavisi üzerindeki etkisidir. Atan ve ark.'nın bir çalışmasında alfa-1 reseptör blokeri ilaç 60 yaş altı ve 60 yaş üzeri BPH ile ilişkili AÜSY olan hastalarda karşılaştırılmıştır. Bu çalışmada 60 yaş altında alfa-1 reseptör blokeri ilacın daha etkili olduğu bulunmuştur. ${ }^{[12]}$ Ancak bu çalışma sonucu diğer çalışmalar ile desteklenmemiştir ve Avrupa Üroloji Derneği kılavuzunun son versiyonunda alfa-1 reseptör blokeri ilaçların her yaş grubunda benzer etkinlikte olduğu belirtilmektedir. ${ }^{[6,13]}$

Prostat volümü ile alfa-1 reseptör blokerlerinin etkinliği arasındaki ilişki de tartışmalı bir diğer konudur. Bazı çalışmalarda alfa-1 reseptör blokerlerinin prostat volümünden bağımsız etki yaptığı saptanmıştır. ${ }^{[14]}$ Ancak Avrupa Üroloji Derneği kılavuzunun son versiyonunda alfa-1 reseptör blokeri ilaçların 1 yıldan kısa süre kullanımlarında etkinlik için prostat volümünün önemli olmadığı, daha uzun süreli kullanımlarda prostat volümü $40 \mathrm{~mL}$ altında ise daha etkin olduğu belirtilmektedir. ${ }^{[6]}$

Alfa-1 reseptör blokeri BPH ile ilişkili AÜSY tedavisinde ilk ve genelde faydalı bir seçenek olmalarına karşın bir grup hastada ilaç bırakılması söz konusudur. Bu ilaçları bırakmanın ilk nedeni küçük bir grup hastada ilaçların beklenen kadar fayda sağlayamamalarıdır. Yaklaşık \%25-30 hastada tedavi başarısızlığı görülebilmektedir. ${ }^{[15]}$ Bir diğer ilacı bırakma nedeni hastalığın progresyonudur. Bu durum tedavi esnasında hastaların yaklaşık \%7'sinde görülebilir. Alfa-1 reseptör bloker tedavisi altında iken progresyon riski fazla olan hastalar yüksek semptom düzeyi ve büyük prostat varlığı ile 100 mm'den uzun intra-vezikal prostatik protrüzyondur. ${ }^{[16-20]}$ Bu durumlar hekimlerin kontrolü dışındaki nedenlerdir. Bir 
grup hastada ise yan etki fazlalığı nedeniyle bu ilaçların kullanımı bırakılmaktadır. ${ }^{[21,22]}$ Alfa-1 reseptör blokeri ilaçlar ile ilgili en önemli yan etkiler kardiovasküler tolerabilite ve cinsel fonksiyonlar ile ilgilidir. Bu ilaçların yan etkileri etkiledikleri alfa-1 reseptör alt tipleri ile direk ilişkilidir. Bu nedenle seçilecek ajana göre yan etki düzeyi kontrol edilebilir.

BPH ile ilişkili AÜSY tedavisinde alfa-1 reseptör blokerlerinin yaygın olarak kullanımı sonrasında elde edilen deneyimler sonucu yıllar içerisinde yeni kullanım alanları gündeme gelmiştir. Alfa-1 reseptör blokeri ilaçların yeni kullanım alanları, akut üriner retansiyon (AÜR) $(\mathrm{BPH}$ ile ilişkili $A \ddot{U} R$ ve postoperatif $A \ddot{U R})$ ve üriner sistem taş hastalığıdır (medikal ekspulsif tedavi için [MET] kullanımı, ekstrakorporeal şok dalga litoripsisi [RIRS] sonrası kullanım, retrograd intrarenal cerrahi [RIRS] öncesi kullanım, D-J stent rahatsızlığı için kullanım). AÜR, BPH'e bağlı veya cerrahi sonrası meydana gelebilmektedir. AÜR geliştiğinde uygulanan tedaviler uretral kateterizasyon ve alfa-1 bloker ilaç kullanımıdır. Uretral kateterizasyon çok etkin bir yöntem olmasına karşın enfeksiyon oluşumu, ağrı, uretral darlık gelişmesi ve maliyet artışı açısından bazı dezavantajlara sahiptir. ${ }^{[23]} \mathrm{Bu}$ nedenle kateter süresinin azaltılması ve etkinliğin devamı için alfa-1 reseptör blokeri ilaçların kullanımı denenmiştir. Kateter alındıktan sonra Alfa-1 bloker ilaç kullanımının spontan miksiyon yapmayı kolaylaştırdığı ve arttırdığı saptanmıştır. ${ }^{[24-26]}$ Çok yeni bir sistemik derleme ve meta-analizde Alfuzosin, Tamsulosin, Silodosin ve Doksazosin'in kateter sonrası spontan miksiyon yapma üzerindeki etkileri araştırılmışır. Bu makalede Alfuzosin ve Tamsulosinin kateter alındıktan sonra daha iyi spontan miksiyon sağladıkları saptanmıştır. ${ }^{[27]}$ AÜR sonrası alfa-1 bloker kullanımının acil cerrahi ihtiyacını azalttığı da gösterilmiştir. ALFOUR faz çalışmasında alfa-2 reseptör blokeri ilaç kullanımı altında iken kateter alındığında $\mathrm{BPH}$ ile ilişkili cerrahi tedavi ihtiyacında azalma ilk ayda $\% 61$, üçüncü ayda \%52 ve altıncı ayda ise \%29 azaldığ saptanmıştır. ${ }^{[24]} \mathrm{BPH}$ ile ilişkili AÜR sonrası acil prostat cerrahisi ihtiyacının azalması çok önemlidir. Çünkü acil $\mathrm{BPH}$ cerrahisi elektif prostatektomiye göre daha morbid ve mortaldir. ${ }^{[28]}$

Kateter alındıktan sonra tekrar AÜR gelişmesini ve cerrahi tedavi ihtiyacını öngörmede bazı yardımcı parametreler vardır. Eğer intravezikal prostatik protrüzyon (IPP) $>10 \mathrm{~mm}$ ise tekrar AÜR gelişmesi ve cerrahi tedavi ihtiyacı büyük oranda meydana gelecektir. ${ }^{[29]}$ Hasta yaşının 65 yaş altında olması, alfa- 1 reseptör bloker ilaç ile $\geq 4$ puan semptomatik düzelmesinin sağlanması, AÜR esnasında mesane kapasitesinin 1 litreden az olduğunun saptanması, PVR'nin $100 \mathrm{~mL}$ altında ölçülmesi tekrar AÜR ve cerrahi ihtiyacının az olacağının göstergeleridir. ${ }^{[4,24]}$
AÜR, ürolojik veya üroloji dışı geçirilmiş cerrahilere bağlı da meydana gelebilir. Buna postoperatif üriner retansiyon (POÜR) adı verilir. POÜR, kompleks ve çok faktörlü bir durumdur. Bunlar hastaya ait risk faktörleri (yaş, cinsiyet), cerrahinin tipi ve süresi, anestezinin tipi, anestezi ve cerrahi esnasında verilen ilaçlar, cerrahi sonrası immobilizasyon, narkotik analjezik kullanımı, intravenöz fazla sıvı verilmesidir. $^{[30,31]}$ Proflaktik alfa-1 reseptör bloker kullanımının POÜR riskini \%20-30 azalttı̆̆ 1 gösterilmiştir. Ancak çalışmalarda alfa-1 reseptör blokerlerinin kullanım ile ilgili bir standart uygulama yoktur. ${ }^{[23,32]}$

Akkoç ve ark.'nın yeni bir çalışmasında spinal anestezi altında ürolojik cerrahiye gitmiş hastalarda POÜR'u önlemek için alfa bloker kullanımının etkisi incelenmiştir. Bu çalışmada hastalar üç gruba ayrılmıştır. Grup 1'e cerrahiden 2 ve 12 saat önce Plasebo PO 2 defa verilmiştir. Grup 2'e cerrahiden 2 ve 14 saat önce Tamsulosin $0,4 \mathrm{mg}$ PO iki defa verilmiştir. Grup 3'e cerrahiden 2 ve 10 saat önce Alfuzosin (ER) $10 \mathrm{mg}$ PO iki defa verilmiştir. Uygulanan cerrahiler hidroselektomi, spermatoselektomi, epididimal kist eksizyonu, skrotal orşiektomi, inguinal orşiektomi, orşiopeksi, peyroni hastalı̆̆ı, konjenital penil kurvatür, perienal ektopik testis cerrahisi, perineal kitle cerrahisi, lenfanjioma sirkumskriptum (inguinal ve perineal) cerrahisidir. Bu çalışmada Alfuzosin ve Tamsulosin'in spinal anestezi sonrası AÜR oluşmasını ve kateterizasyon ihtiyacını azalttığı bulunmuştur. ${ }^{[33]}$

POÜR tedavisinde proflaktik alfa-1 bloker kullanımının gerçek etkisini değerlendirmek için anestezinin tipi (spinal, epidural, genel) ve preoperatif kullanılan ilacın tipi, dozu, verilme zamanının standart hale getirilmesi için kapsamlı çalışmalara gerek vardır. AÜR sonrası kateterizasyon süresi tartışmalıdır. Çalışmalarda AÜR sonrası 3 günlük kateterizasyonun yeterli olduğu görüşü hakimdir. Daha uzun kateterizasyonun komplikasyonları arttırdığı ve spontan miksiyon üzerine ise anlamlı etkisinin olmadı$\breve{g}_{1}$ saptanmıştır. ${ }^{[34]}$ Kateter alınmadan önce ne süre alfa-1 bloker verileceği konusu da tartışmalıdır. Cochrane veri tabanında, kateter alınmadan önce 3 gün alfa-1 bloker alınması kateter sonrası spontan miksiyon başarısını arttırdığı belirtilmektedir. ${ }^{[35]}$

Alfa-1 reseptör blokerlerinin giderek artan yeni bir kullanım alanı üriner sistem taş hastalığında MET amacıyla kullanımıdır. Hem Cochrane sistemik analizinde hem de Avrupa Üroloji Derneği kılavuzunun en son versiyonunda erişkin hastalarda 5 mm'den büyük ureter taşlarının tedavisinde MET amacıyla kullanımı önerilmektedir. Avrupa Üroloji Derneği kılavuzunda kanıt düzey 1a, öneri düzeyi güçlüdür. ${ }^{[6,36]}$ 
Üriner sistem taş hastalığında bir diğer endikasyon alfa-1 reseptör blokerlerinin ESWL sonrası kullanımıdır. Bu konuda yapılmış çalışmalarda taşın düşme oranı, taşın düşme süresi, az analjezik kullanımı konusunda faydalı olduğu gösterilmiştir. ${ }^{[37-39]}$ Ayrıca bir diğer çalışmada alfa-1 reseptör blokeri ilaçların ESWL sonrası endoskopik işlem ihtiyacında azalma sağladığı da saptanmıştır. ${ }^{[40]}$ Son yıllarda alfa-1 reseptör blokeri ilaçların RIRS öncesinde kullanıldığı çalışmalarda vardır. Erturhan ve ark.'nın çalışmasında RIRS öncesi 25 hastaya 2 hafta alfa-1 reseptör blokeri ilaç verilmiştir, 25 hastaya alfa-1 reseptör bloker bir ilaç verilmemiştir. Araştırıcılar, alfa-1 reseptör blokeri verilen ve verilmeyen gruplar arasında ilk denemede ureteral akses kılıfının başarılı şekilde takılıp takılmadığını karşılaştırmışlardır. Alfa-1 reseptör bloker ilaç alan grupta başarılı kılıf takılması \%65,2 iken ilaç verilmeyen grupta bu oran \%44 bulunmuştur Aradaki fark istatistiksel olarak anlamlı olmasa da rakamsal olarak alfa-1 reseptör blokeri kullanan grupta ilk denemede başarılı akses kılıf takılmasının daha yüksek oranda yapıldığı görülmektedir. ${ }^{[41]}$ Bir diğer çalışmada preoperatif alfa-1 reseptör blokeri kullanımının akses kılıf takılması esnasında uygulanan güç üzerine etkisi incelenmiştir. Alfa-1 reseptör bloker alanlarda kılıf takılması esnasında uygulanan gücün önceden stent takılmış olanlara benzer olduğu ve ayrıca ureter hasarının daha az olduğu saptanmıştır. ${ }^{[42]}$

Alfa-1 reseptör blokeri ilaçlar D-J rahatsızlığını azaltmak için de denenmiştir. Yapılmış çalışmalarda D-J stent takılmış hastalarda stentin rahatsızlığını gidermek için en çok çalışılan alfa-1 reseptör blokerler alfuzosin ve tamsulosindir. $\mathrm{Bu}$ çalışmalarda alfa-1 reseptör blokeri ilaçların ciddi fayda sağladıkları saptanmıştır. ${ }^{[43-45]}$ Alfa-1 reseptör blokeri ilaçların bu faydayı nasıl sağladığı konusu tartışmalıdır. D-J stentin oluşturduğu rahatsızlığın, mesanenin glikozaminoglikan (GAG) tabakasında azalmaya yol açması ile ilişkili olduğu belirtilmiştir. Alfa-1 reseptör blokeri ilaçlar GAG tabakasındaki bu kaybı azaltarak fayda sağladığı düşünülmektedir. ${ }^{[46]}$ Çok yeni randomize kontrollü çalışmaların değerlendirildiği bir sistematik derleme ve meta-analizde ureteroskopi öncesi alfa-1 reseptör kullanımının ureteral orifis dilatasyon ihtiyacını azalttığı, takiplerde taşsızlık oranını arttırdığı, ureteroskop ile taşa ulaşımı kolaylaştırdığı ve buna bağlı operasyon süresini kısalttığı belirtilmektedir. [47] Stente bağlı yakınmaların giderilmesinde sadece alfa-1 reseptör blokerler yeterli olmaz ise alfa-1 reseptör bloker ve antimuskarinik kombinasyon tedavisi de verilebilir. ${ }^{[48-50]}$

Alfa-1 reseptör blokeri ilaçların eski ve yeni tüm endikasyonlarında dikkate alınması gerekli bazı konular vardır. Bunlar hastanın yaşı, mobilite durumu ve artmış düşme riskinin varlığı, kardiyovasküler hastalık, antihipertansif ilaç kullanımı, ereksiyon bozukluğu nedeniyle vazodilatasyon yapan ilaç alımı ve cinsel fonksiyonlardır. ${ }^{[51]}$ Yaşı 66 üzeri olan erkeklerde, alfa-1 reseptör blokere bağlı hipotansiyon gelişmesinden dolayı düşme ve kırık olma riskinin arttığı saptanmıştır. ${ }^{[52]}$ Alfa-1 reseptör blokeri ilaçlar ile ilgili çok önemli bir sorun kardiyovasküler tolerabilitedir. Alfa-1 reseptör blokeri ilaçlar içerisinde en fazla vazodilatasyon yapıcı etki doksazosin ve terazosinde görülür iken bu yan etkinin en az olduğu ilaçlar ise alfuzosin ve tamsulosindir. ${ }^{[53]}$ Tamsulosin, Silodosin ve Alfuzosin, Terazosin ve Doksazosin'e göre daha az hipotansiyon ve senkop yaptığ1 gösterilmiştir. ${ }^{[14,54-56]}$ Zhang ve ark.'nın bir çalışmasında Alfuzosin 10 mg'ın kan basıncı üzerinde klinik olarak anlamlı bir etkisi olmadığı için antihipertansif ilaç alanlar ve hipotansiyon riski olan kişiler tarafından kullanabileceği saptanmıştır. ${ }^{[57]}$

Alfa-1 reseptör blokeri ilaçların cinsel fonksiyon üzerindeki etkileri de hastalar tarafından dikkate alınan bir diğer konudur. Yapılan çalışmalarda bu ilaçların libido üzerine etki yapmadıkları, ereksiyon açısından etkilerinin net olmadığı ancak ejakulasyon bozukluğu (EjB) oluşturdukları (retrograd ejakulasyon, emisyon yokluğu) saptanmıştır. ${ }^{[58]}$ EjB açısından tamsulosin (\%35) ve silodosin (\%28) en fazla bu yan etkiyi oluşturur iken doksazosin ve terazosinin çok az EjB yaptığ 1 belirtilmektedir. ${ }^{[54,59,60]}$ Alfuzosinin ise EjB yapmadığı saptanmıştır. ${ }^{[61]}$ Amerikan Üroloji Derneği Kılavuz komitesi tüm alfa-1 blokerlerin benzer bir klinik etkinliğe sahip olduğunu ancak alfuzosinin ejakulasyon bozukluğu oluşturmadığını belirtmektedir. ${ }^{[62]}$

Erekiyon bozukluğu için fosfodiesteraz tip-5 inhibitörü (PDE-5i) ilaç kullanan hastalarda alfa-1 reseptör blokeri ilaçların da gerekli hale gelebileceği bilinmektedir. Bu hastalarda kombinasyon tedavisi için dikkate alınması gereken konu iki ilacın artmış hipotansif etkisidir. PDE-5i ilaç ile beraber terazosin ve doksazosin kullanımının hipotansif etkiyi arttırabileceği endişesi vardır. Bu hastalarda alfuzosin, tamsulosin ve silodosin kullanımının daha uygun olduğu belirtilmektedir. Bu ilaçlar tercih edildiğinde bile iki ilaç alımı arasında en az 4 saatlik bir sürenin olmasının gerekli olduğu da belirtilmektedir. ${ }^{[63]}$

Sonuç olarak, BPH ile ilişkili AÜSY tedavisinde alfa-1 reseptör blokeri ilaçlar yaştan bağımsız olarak etkili ilk tercih edilen tıbbi tedavi seçeneğidir. Buna ek olarak AÜR tedavisinde de alfa-1 reseptör blokerler faydalı olmaktadır. Diğer klinik kullanım alanları için standart uygulamalar geliştirmek amacıyla geniş kapsamlı çalışmalara ihtiyaç vardır. Ancak tüm kullanımlarda hangi alfa-1 reseptör blokeri ilacın seçileceği kararı kardiyovasküler sistem ve cinsel fonksiyonlar üzerindeki yan etkileri dikkate alınarak verilmelidir. 


\section{Hakem Değerlendirmesi}

Dış bağımsız

Çıkar Çatışması

Yazarlar çıkar ilişkisi olmadığını beyan etmişlerdir.

\section{Finansal Destek}

Herhangi bir mali destek alınmamıştır.

\section{Peer-review}

Externally peer-reviewed.

\section{Conflict of Interest}

No conflict of interest was declared by the authors.

\section{Financial Disclosure}

No financial disclosure was received.

\section{KAYNAKLAR}

1. Caine M, Raz S, Zeigler M. Adrenergic and cholinergic receptors in the human prostate, prostatic capsule and bladder neck. BJU 1975;47:193202. [CrossRef]

2. Bartsch G, Müller HR, Oberholzer M, Rohr HP. Light microscopic stereological analysis of the normal human prostate and of benign prostatic hyperplasia. J Urol 1979;122:487-9. [CrossRef]

3. Roehrborn CG, Schwinn DA. Alpha1-adrenergic receptors and their inhibitors in lower urinary tract symptoms and benign prostatic hyperplasia. J Urol 2004;171:1029-35. [CrossRef]

4. Emberton M, Fitzpatrick JM, Rees J. Risk stratification for benign prostatic hyperplasia (BPH) treatment. BJU Int 2011;107:876-80. [CrossRef]

5. Gül ZG, Kaplan SA. BPH. Why Do Patients Fail Medical Therapy? Curr Urol Rep 2019;20:40. [CrossRef]

6. Gravas S, Cornu JN, Gacci MC, Gratzke C, Herrmann TRW, Mamoulakis C, et al. Management of Non-neurogenic Male LUTS, 2020. https:// uroweb.org/guideline/treatment-of-non-neurogenic-male-luts/

7. McVary KT, Roehrborn CG, Avins AL, Barry MJ, Bruskewitz RC, Donnell $\mathrm{RF}$, et al. Update on AUA guideline on the management of benign prostatic hyperplasia. J Urol 185:1793-803. [CrossRef]

8. Roehrborn CG and Siegel RL. Safety and efficacy of doxazosin in benign prostatic hyperplasia: a pooled analysis of three double-blind, placebocontrolled studies. Urology 1996;48:404-15. [CrossRef]

9. Samli MM and Dincel C. Terazosin and doxazosin in the treatment of $\mathrm{BPH}$. results of a randomized study with crossover in non-responders. Urol Int 2004;73:125-9. [CrossRef]

10. Senkul T, Yilmaz O, Iseri C, Adayener C, Akyol I, Ates F. Comparing the therapeutic outcome of different alpha-blocker treatments for $\mathrm{BPH}$ in the same individuals. Int Urol Nephrol 2008;40:663-6. [CrossRef]

11. Karadağ E, Öner S, Budak YU, Atahan Ö. Randomized crossover comparison of tamsulosin and alfuzosin in patients with urinary disturbances caused by benign prostatic hyperplasia. Int Urol Nephrol 2011;43:949-54. [CrossRef]

12. Atan A, Başar MM, Yıldız M, Akalın Z. The effect of age in the usage of alpha receptor blocker treatment in prostate patients. Arch Ital Urol Androl 1997;69:299-301. https://pubmed.ncbi.nlm.nih.gov/9477614/

13. Michel MC, Mehlburger L, Bressel HU, Goepel M. Comparison of tamsulosin efficacy in subgroups of patients with lower urinary tract symptoms. Prostate Cancer Prostatic Dis 1998;1:332-5. [CrossRef]

14. Roehrborn CG, Van Kerrebroeck P, Nordling J. Safety and efficacy of alfuzosin $10 \mathrm{mg}$ once-daily in the treatment of lower urinary tract symptoms and clinical benign prostatic hyperplasia: a pooled analysis of three double-blind, placebo-controlled studies. BJU Int 2003;92:257-61. [CrossRef]

15. Shapiro $E$, Hartanto $V$, Lepor $H$. The response to alpha blockade in benign prostatic hyperplasia is related to the percent area density of prostate smooth muscle. Prostate 1992;21:297-307. [CrossRef]

16. Hong SJ, Ko WJ, Kim SI, Chung BH. Identification of baseline clinical factors which predict medical treatment failure of benign prostatic hyperplasia: an observational cohort study. Eur Urol 2003;44:94-100. [CrossRef]
17. Hong KP, Byun YJ, Yoon H, Park YY, Chung WS. Prospective factor analysis of alpha blocker monotherapy failure in benign prostatic hyperplasia. Korean J Urol 2010;51:488-91. [CrossRef]

18. Hirayama K, Masui K, Hamada A, Shichiri Y, Masuzawa N, Hamada S. Evaluation of Intravesical Prostatic Protrusion as a Predictor of Dutasteride-Resistant Lower Urinary Tract Symptoms/Benign Prostatic Enlargement With a High Likelihood of Surgical Intervention. Urology 2015;86:565-9. [CrossRef]

19. Kalkanli A, Tandogdu Z, Aydin M, Karaca AS, Hazar Al, Balci MB, et al. Intravesical Prostatic Protrusion: A Potential Marker of Alpha-blocker Treatment Success in Patients With Benign Prostatic Enlargement. Urology 2016;88:161-5. [CrossRef]

20. Topazio L, Perugia C, De Nunzio C, Gaziev G, Lacovelli V, Bianchi D, et al. Intravescical prostatic protrusion is a predictor of alpha blockers response: results from an observational study. BMC Urol 2018;18:6. [CrossRef]

21. McConnell JD, Roehrborn CG, Bautista OM, Andriole GL Jr, Dixon CM, Kusek JW, et al. The long-term effect of doxazosin, finasteride, and combination therapy on the clinical progression of benign prostatic hyperplasia. N Engl J Med 2003;349:2387-98. [CrossRef]

22. Verhamme KM, Dieleman JP, Bleumink GS, Bosch JL, Stricker BH, Sturkenboom MC. Treatment strategies, patterns of drug use and treatment discontinuation in men with LUTS suggestive of benign prostatic hyperplasia: the Triumph project. Eur Urol 2003;44:539-45. [CrossRef]

23. Ghuman A, de Jonge SW, Dryden SD. Feeney T, Buitrago DH, Phang PT. Prophylactic use of alpha-1 adrenergic blocking agents for prevention of postoperative urinary retention: A review \& meta-analysis of randomized clinical trials. Am J Surg 2018;215:973-9. [CrossRef]

24. McNeill SA, Hargreave TB, Roehrborn CG; Alfaur Study Group. Alfuzosin $10 \mathrm{mg}$ once daily in the management of acute urinary retention: results of a double-blind placebo-controlled study. Urology 2005;65:83-9. [CrossRef]

25. Desgrandchamps F, De La Taille A, Doublet JD; RetenFrance Study Group. The management of acute urinary retention in France: a crosssectional survey in 2618 men with benign prostatic hyperplasia. BJU Int 2006;97:727-33. [CrossRef]

26. Guang-Jun D, Feng-Bin G, Xun-Bo J. A1-blockers in the management of acute urinary retention secondary to benign prostatic hyperplasia: a systematic review and meta-analysis. Ir J Med Sci 2015;184:23-30. [CrossRef]

27. Karavitakis M, Kyriazis I, Omar MI, Gravas S, Cornu JN, Drake MJ, et al. Management of urinary retention in patients with Benign Prostatic Obstruction: A systematic review and meta-analysis. Eur Urol 2019;75:788-98. [CrossRef]

28. Pickard R, Emberton M, Neal DE; National Prostatectomy Audit Steering Group. The management of men with acute urinary retention. Br J Urol 1998;81:712-20. [CrossRef]

29. Tiong HY, Tibung MJ, Macalalag M, Li MK, Consigliere D. Alfuzosin $10 \mathrm{mg}$ once daily increases the chances of successful trial without catheter after acute urinary retention secondary to benign prostate hyperplasia. Urol Int 2009;83:44-8. [CrossRef]

30. Baldini G, Bagry H, Aprikian A, Carli F, Warner DS, Warner MA Postoperative urinary retention: anesthetic and perioperative considerations. Anesthesiology 2009;110:1139-57. [CrossRef]

31. Chen J, Matzkin H, Lazauskas T, Lelcuk S, Braf Z. Posthernioplasty urinary retention: a noninvasive work-up for prediction. Urol Int 1993;51:243-5. [CrossRef]

32. Clancy C, Coffey JC, O'Riordain MG, Burke JP. A meta-analysis of the efficacy of prophylactic alpha-blockade for the prevention of urinary retention following primary unilateral inguinal hernia repair. Am J Surg 2018;216:337-41. [CrossRef]

33. Akkoc A, Aydin C, Topaktas R, Kartalmis M, Altin S, Isen K, Metin A. Prophylactic effects of alpha-blockers, Tamsulosin and Alfuzosin, on postoperative urinary retention in male patients undergoing urologic surgery under spinal anaesthesia. Int Braz J Urol 2016;42:578-84. [CrossRef] 
34. Yoon PD, Chalasani V, Woo HH. Systematic review and meta-analysis on management of acute urinary retention. Prostate Cancer Prostat Dis 2015;18:297-302. [CrossRef]

35. Fisher E, Subramonian K, Omar MI. The role of alpha blockers prior to removal of urethral catheter for acute urinary retention in men. Cochrane Database Syst Rev 2014;6:CD 006744. [CrossRef]

36. Campschroer T, Zhu X, Vernooij RWM, Lock TMTW. a-blockers as medical expulsive therapy for ureteric stones: a Cochrane systematic review. BJU Int 2018;122:932-45. [CrossRef]

37. Seitz C, Liatsikos E, Porpiglia F, Tiselius HG, Zwergel U. Medical therapy to facilitate the passage of stones: what is the evidence? Eur Urol 2009;56:455-71. [CrossRef]

38. Kobayashi M, Naya Y, Kino M, Awa Y, Nagata M, Suzuki $H$, et al. Low dose tamsulosin for stone expulsion after extracorporeal shock wave lithotripsy: efficacy in Japanese male patients with ureteral stone. Int J Urol 2008;15:495-8. [CrossRef]

39. Küpeli B, Irkilata L, Gürocak S, Tunç L, Kiraç M, Karaoglan U, Bozkirli I. Does tamsulosin enhance lower ureteral stone clearance with or without shock wave lithotripsy? Urology 2004;64:1111-5. [CrossRef]

40. El Said NO, El Wakeel L, Kamal KM, Morad AER. Alfuzosin treatment improves the rate and time for stone expulsion in patients with distal uretral stones: a prospective randomized controlled study. Pharmacotherapy 2015;35:470-6. [CrossRef]

41. Erturhan S, Bayrak Ö, Şen H, Yılmaz AE, Seçkiner I. Can alpha blockers facilitate the placement of ureteral access sheaths in retrograde intrarenal surgery? Turk J Urol 2019;45:108-12. [CrossRef]

42. Koo KC, Yoon JH, Park NC, Lee HS, Ahn HK, Lee KS, et al. The impact of preoperative a-adrenergic antagonists on ureteral access sheath insertion force and the upper limit of force required to avoid ureteral mucosal injury: A randomized controlled study. J Urol 2018;199:162230. [CrossRef]

43. Lamb AD, Vowler SL, Johnston R, Dunn N, Wiseman OJ. Meta-analysis showing the beneficial effect of a-blockers on ureteric stent discomfort. BJU Int 2011;108:1894-902. [CrossRef]

44. He F, Man LB, Li GZ, Liu N. Efficacy of a-blocker in improving ureteral stent-related symptoms: a meta-analysis of both direct and indirect comparison. Drug Des Devel Ther 2016;10:1783-93. [CrossRef]

45. Fischer KM, Louie M, Mucksavage P. Ureteral stent discomfort and its management. Curr Urol Rep 2018;19:64. [CrossRef]

46. Liu S, Yu Y, Gao Y, Yang X, Pang Z. Decreased urinary glycosaminoglycan excretion following alfuzosin treatment on ureteral stent-related symptoms: a prospective, randomized, placebo-controlled study. Urolithiasis 2016;44:185-90. [CrossRef]

47. Alsaikhan B, Koziarz A, Lee JY, Pace KT. Preoperative Alpha-Blockers for Ureteroscopy for Ureteral Stones: A Systematic Review and MetaAnalysis of Randomized Controlled Trials. J Endourol 2020;34:33-41. [CrossRef]

48. Zhou L, Cai X, Li H, Wang KJ. Effects of a-Blockers, Antimuscarinics, or Combination Therapy in Relieving Ureteral Stent-Related Symptoms: A Meta-Analysis. J Endourol 2015;29:650-6. [CrossRef]
49. Zhang YM, Chu $P$, Wang WJ. PRISMA-combined a-blockers and antimuscarinics for ureteral stent-related symptoms: A meta-analysis. Medicine 2017;96:e6098. [CrossRef]

50. Yan H, Wang Y, Sun R, Cui Y. The Efficacy of Antimuscarinics Alone or in Combination with Alpha-Blockers for the Treatment of Ureteral StentRelated Symptoms: A Systematic Review and Meta-Analysis. Urol Int 2017;99:6-13. [CrossRef]

51. Fine SR, Ginberg P. Alpha-adrenergic receptor antagonists in older patients with benign prostatic hyperplasia: issues and potential complications. J Am Osteopath Assoc 2008;108:333-7. https://jaoa. org/article.aspx?articleid=2093615

52. Welk B, McArthur E, Fraser LA, Hayward J, Dixon S, Hwang YJ, Ordon M. The risk of fall and fracture with the initiation of a prostate-selective a antagonist: a population based cohort study. BMJ 2015;351:h5398. [CrossRef]

53. Nickel JC, Sander S, Moon TD. A meta-analysis of the vascular-related safety profile and efficacy of alpha-adrenergic blockers for symptoms related to benign prostatic hyperplasia. Int J Clin Pract 2008;62:154759. [CrossRef]

54. Lee M. Tamsulosin for the treatment of benign prostatic hypertrophy. Ann Pharmacother 2000;34:188-99. [CrossRef]

55. Marks LS, Gittelman MC, Hill LA, Volinn W, Hoel G. Rapid efficacy of the highly selective alpha1A-adrenoceptor antagonist silodosin in men with signs and symptoms of benign prostatic hyperplasia: pooled results of 2 phase 3 studies. J Urol 2009;181:2634-40. [CrossRef]

56. Rees J, Bultitude M, Challacombe B. The management of lower urinary tract symptoms in men. BMJ 2014;348:g3861. [CrossRef]

57. Zhang LT, Lee SW, Park K, Chung WS, Kim SW, Hyun JS, et al. Multicenter, prospective, comparative cohort study evaluating the efficacy and safety of alfuzosin $10 \mathrm{mg}$ with regard to blood pressure in men with lower urinary tract symptoms suggestive of benign prostatic hyperplasia with or without antihypertensive medications. Clin Interv Aging 2015;10:277-86. [CrossRef]

58. van Dijk MM, de la Rosette JJ, Michel MC. Effects of alpha(1)adrenoceptor antagonists on male sexual function. Drugs 2006;66:287301. [CrossRef]

59. Gacci M, Ficarra V, Sebastianelli A, Corona G, Serni S, Shariat SF, et al. Impact of medical treatments for male lower urinary tract symptoms due to benign prostatic hyperplasia on ejaculatory function: a systematic review and meta-analysis. J Sex Med 2014;11:1554-66. [CrossRef]

60. Lepor H, Kazzazi A, Djavan B. a-Blockers for benign prostatic hyperplasia: the new era. Curr Opin Urol 2012;22:7-15. [CrossRef]

61. Giuliano F. Impact of medical treatments for benign prostatic hyperplasia on sexual function. BJU Int 2006;97:34-8. [CrossRef]

62. Roehrborn and the AUA BPH Guideline Update Panel. Guideline on the management of benign prostatic hyperplasia (BPH). 2003; chapters 1-23. http://www.auanet.org/guidelines/bph.cfm

63. Cunningham GR and Kadmon D, 2020. h t t p s : / / w w w. u p tod a t e.com/contents/ medical-treatment-of-benign-prostatic-hyperplasia\#H239931225 